\section{SCIDoc Publishers}

\title{
Qualitative Detection of Proviral-DNA of HIV-1 In Infants To Determine The Efficacy of Antiretroviral Therapy In The Prevention of Vertical Transmission of HIV-1 In The Gambia
}

Research Article

\author{
Lamin B. Cham ${ }^{1,3 *}$, Ousman Bah $\mathrm{P}^{2}$, Sembène $\mathrm{PM}^{3}$, Ceesay $\mathrm{M}^{1}$, Joof $\mathrm{E}^{1}$, Kebbeh $\mathrm{A}^{1}$, Gueye $\mathrm{M}^{3}$, Njie E $\mathrm{E}^{4}$, Sanneh B \\ ${ }^{1}$ National Public Health Laboratories, Ministry of Health and Social Welfare, Kotu Layout, Kotu, The Gambia, West Africa. \\ ${ }^{2}$ National AIDS Control Program, Ministry of Health and Social Welfare, The Gambia, West Africa. \\ ${ }^{3}$ University Cheikh Anta Diop de Dakar, Senegal, West Africa. \\ ${ }^{4}$ University of the Gambia, The Gambia, West Africa.
}

\section{Abstract}

Background: The priority of the Gambia government is to eliminate maternal to child transmission of HIV and in line with this priority, the country implemented an antiretroviral therapy (ART) program. With this, all HIV infected pregnant and breastfeeding mothers and infants have access to ARV drugs. This study aims to determine the prevalence of vertical transmission of HIV among women receiving the ARV drugs.

Methods: Dried blood spot samples were collected from 109 HIV-exposed infants enrolled in 13 PMTCT sites across the country. A qualitative detection of proviral-DNA of HIV-1 was performed using the Real Time Abbott PCR assay. Data from 105 mothers were analyzed using SPSS version 16.0 and association of risk factors to PCR results were analyzed using (Crosstabs) Pearson Chi-Square. The $\mathrm{p}$-value of significant was set at $\mathrm{p}<0.05$.

Results: This study has found the prevalence of vertical transmission of HIV is $0.0 \%(0 / 64)$ among women that received the ARV prophylaxis then started ART, 7.1\% (2/28) among mothers that received HIV prophylaxis only, and 38.4\% (5/13) among women who neither receive HIV-prophylaxis nor ART during pregnancy or breastfeeding. Other risk factors of vertical transmission such as late initiation of treatment, default during treatment and first born of twins were found to be significantly associated with vertical transmission $\mathrm{p}=0.001, \mathrm{p}=0.022$ and $\mathrm{p}=0.000$ respectively.

Conclusion: This study has found that the early intervention of ART at the onset of pregnancy through breastfeeding can eliminates Maternal to Child transmission of HIV and a high risk of vertical transmission was found among women who neither receive prophylaxis nor ART. If the effectiveness of the antiretroviral therapy is maintain, the Gambia, in the near future will attain the WHO's goal to eliminate Maternal to Child transmission of HIV.

Keywords: ARV Drugs; ART, Pophylaxis, Maternal to Child (Vertical) Transmission; PCR; HIV-Exposed Infants; The Gambia.

\section{Background}

The climatic and other environmental factors of the African continent encourages the adaptation and survival of most microorganisms (pathogens inclusive). This has caused infectious diseases to be a major challenge in the socio-economic status of countries in the Sub- Saharan Africa. One of the leading pathogenic virus that causes serious public health challenge is the Human Immunodeficiency Virus (HIV).
The Human Immunodeficiency Virus (HIV) is an etiological cause of Acquired Immunodeficiency Syndrome (AIDS) [7, 12, 22] which is a major worldwide threat particularly in Africa as it continue to claims millions of lives and still remind incurable. Globally, over 35.4 million people are living with the HIV and about $63-70 \%$ of the HIV infected individuals at the end of 2012 are living in Sub-Saharan Africa $[15,18]$. The Sub-Saharan Africa represent $10 \%$ of the world's population but unfortunately $67 \%$

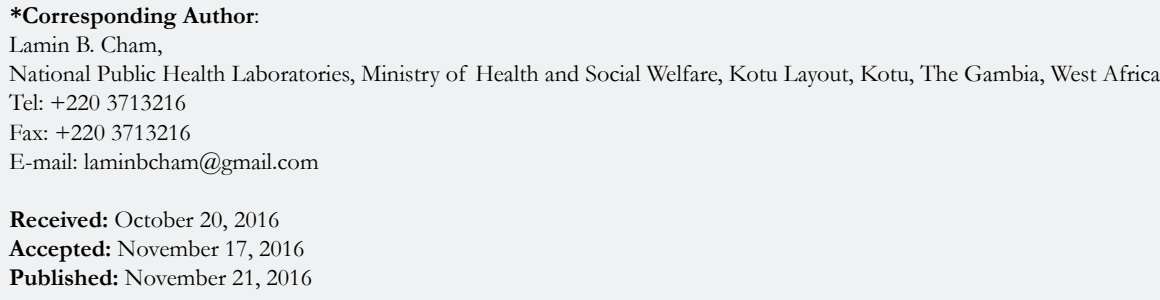

Citation: Lamin B. Cham, Ousman Bah P, Sembène PM, Ceesay M, Joof E, et al., (2016) Qualitative Detection of Proviral-DNA of HIV-1 In Infants To Determine The Efficacy of Antiretroviral Therapy In The Prevention of Vertical Transmission of HIV-1 In The Gambia. Int J AIDS Res. 3(9), 138-142. doi: http://dx.doi.org/10.19070/2379-1586-1600027 
of HIV infected adults and $90 \%$ of HIV infected children live in Sub-Saharan Africa and about three quarters of all AIDS deaths occurred in this region (WHO report. 2013; [14]). It is estimated that roughly there are 7000 new HIV infections every day and nearly $97 \%$ of these, come from developing countries and about 60\% are from Sub-Saharan Africa [22].

The Gambia has a population of 1.8 million with a growth rate of $3.3 \%$ and the current HIV prevalence is at $1.57 \%$ for HIV-1 and $0.26 \%$ for HIV-2. The Gambia like other West African countries has a low prevalence of HIV. It was first diagnosed in May 1986 and by 1999 , there were 810 new cases detected [13]. The HIV-1 has a prevalence of $0.6 \%$ in 1993 to $2.1 \%$ in 2004, then later drop to $1.1 \%$ in 2005 and then shot to $2.8 \%$ in 2006 . The prevalence was then stabilize between $2.8 \%$ to $1.57 \%$ from 2006 to 2013 due to the intervention of different HIV prevention and control programs [14].

The priority of the government of the Gambia is to reduce the HIV prevalence to less than $1 \%$ and in line to this priority, the Gambia has developed different means of preventing of HIV infections and among these, is the Elimination of Mother to Child Transmission of HIV. With this program, the country has aimed at reducing transmission from mother to child to less than $4 \%$.

The Prevention of mother To Child Transmission (PMTCT) program in the Gambia provides free and easy access to ARV drugs to all HIV infected pregnant and breastfeeding women and their children. The national coverage of the PMTCT program is very wide across the country. About $60 \%$ of these patients are enrolled in the public health facilities and $40 \%$ in private facilities. Forty four percent $(44 \%)$ of the patients are enrolled in two urban sites showing the concentration of the services in major urban areas, yet a massive decentralization of PMTCT sites have been done in 2016. This treatment was initially monitored using a routine CD4 analysis and now all patients on ART are run for viral load.

The antiretroviral drugs used in the Gambia are combination of Nucleoside Reverse Transcriptase Inhibitor (NRTIs), NonNucleoside Reverse Transcriptase Inhibitor (NNRTIs) and Protease Inhibitor (PIs). The NRTIs used are Zidovudine (AZT), Abacavir (ABC), Emtricitabin (3TC) and Tenofovir (TDF) and the NNRTIs used are Niverapine (NVP), Efavirenz (EFV) and the protease inhibitors are Liponavir (LPV) or Ritonavi [13]. The dosages for pregnant and breast feeding mother and children infected with HIV-1 differ from those of HIV-2, this is because HIV-2 is naturally resistant to NNRTIs.

- Adult with HIV-1: TDF + 3TC + EFV (alternative;
AZT+3TC+NVP/LPV)
- Adults with HIV-2: AZT + 3TC + TDF (alternative;
AZT+3TC+ABC/LPV)
- Children: AZT syrup twice daily or NVP dose daily.

In addition to the PMTCT, HIV patients receiving the ARV drugs are also given Cotrimazole as a prophylaxis for opportunistic infections. Despite this recent optimization of antiretroviral drugs, the country continues to register new HIV pediatric infections.

In August 2015, the Gambia established a new molecular biology laboratory (DNA \& RNA PCR) purposely for the early infant diagnostic (EID) for HIV and monitoring the adherence of patients receiving the antiretroviral drugs. With this, all children born and breastfeeding from HIV infected mothers are tested (using PCR) at birth or during breastfeeding. Though EID is very challenging because of the cost and complexity of collecting, transporting and testing of biological samples but it is crucial for the timely initiation of ARVs to reduce child mortality.

\section{Methods}

\section{Ethical Consideration}

This study was reviewed and approved by the Gambia Scientific and Ethic Committee and the reference number of ethical clearance certificate is SCC1475v2. It was also approved and funded by the National AIDS Secretariat (NAS) and all data for the analysis were abstracted from their routine collected HIV information in the Gambia.

\section{Study Subjects and Design}

A total number of 109 samples were collected from infants born and breastfeeding from HIV infected mother receiving the combined ARVs drugs as lifelong therap. Few drops of infant's blood sample $(50 \mathrm{uL})$ were collected on a Whatman 903 card, air dry, stored at $10 \mathrm{C}$ and transported to the National Public Health Laboratories (Reference Lab) in a form of Dried Blood Spot (DBS). These samples we collected from 6 hospitals and 7 health centers across the country. These includes Bansang Hospital, Bwiam Hospital, Jammeh Foundation Hospital, Edward Francis Small Teaching Hospital, Serekunda General Hospital and Farafenni Hospital, Hands on Care Health Center, Sibanor Health center, SOS Health center, Soma Health center, Kudang Health center, Kuntaur health center and Basse Health Center.

\section{Data Collection and Analysis}

Each mother was given an identification number and data on HIV related issues were abstracted from HIV treatment sites. Information such as mother's age, date of delivery, number of parity, number of infected child, duration of breastfeeding, treatment site, date of initiation of ARVs, duration on ARVs, CD4 cell count before delivery, last viral load etc. These categorical data were analyzed using SPSS version 16.0 software. Pearson Chi-square test by Crosstabs method was used to determine the association of risk factors. The statistical significant value was set at $\mathrm{p}<0.05$.

\section{DNA Extraction and Detection of Proviral DNA}

Two to three circles of about $50 \mathrm{uL}$ were cut from the Whatman 903 card and transferred into a $50 \mathrm{~mL}$ falcon tube and $1.7 \mathrm{~mL}$

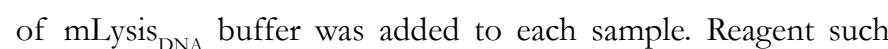
as mLysis buffer, mWash1 solution, mWash2 solution, Microparticles (Magnetic particles), and Elution buffer were used during DNA extraction. 70\% ethanol was added to both the mLysis buffer and the mWash solutions, $35 \mathrm{~mL}$ of ethanol was added to a $70 \mathrm{~mL}$ of mlysis buffer, $23 \mathrm{~mL}$ ethanol was added to a $46 \mathrm{~mL}$ of mWash1 and $70 \mathrm{~mL}$ ethanol was added to a $46 \mathrm{~mL}$ of mWash2. $750 \mathrm{uL}$ of the Internal Control (IC) was added to each bottle of 
the mLysis buffer ethanol solution. $13 \mathrm{~mL}$ of mMicropaticles (Magnetic particles) and $11 \mathrm{~mL}$ of Elution buffer were also used.

The Amplification Master-mix consist of 271uL of HIV-1 Activation reagent, $979 \mathrm{uL}$ of HIV-1 Oligonucleotide and a Thermostable DNA polymerase enzyme reagents were used for HIV-1 proviral-DNA amplification. These reagents were thaw at $15^{*} \mathrm{C}$ and loaded into the m2000sp machine. An Abbott 96-wells Optical Reaction plate (PCR- plate) was place on the Eppendorf PCR cooler, a disposable deep-well plate and disposable tips were also loaded to the m2000sp machine.

After the extracted nucleic acid were transferred to the PCR Optical reaction plate, the PCR plate was sealed and transferred to the m2000rt machine for the reverse transcription of HIV-1 RNA to $c D N A$ and detection of any extracted HIV-1 proviral-DNA.

\section{Results}

Between May-July 2016, a total number of 109 HIV-exposed infants whose mothers are currently receiving the combined antiretroviral therapy were tested to evaluate the prevalence of vertical transmission of HIV using the Reverse Transcriptase Polymerase Chain Reaction (rt-PCR) technique. Out of these 109 HIV-exposed infants, 7 (6.4\%) were found positive.

\section{Baseline Characteristic of Infants and Their Mothers}

All the 109 HIV exposed infants were on exclusive breastfeeding. Among these, 47.7\% (52/109) have exclusively breastfed for 02 months, $25.6 \%$ (29/109) for 02 to 04 months, and $25.7 \%(28 / 109)$ have exclusively breastfed for 06 months. Among these infants, 10 infants were born as twins. Among the 105 mothers, 60.9\% (64/105) mothers received the HIV prophylaxis then started ART during pregnancy and breastfeeding, 26.6\% (28/105) mothers received only prophylaxis during pregnancy and breastfeeding and $12.3 \%(13 / 105)$ mothers never receive prophylaxis or ART during pregnancy and breastfeeding. Among these, 15.2\% (16/105) mothers had late to start prophylaxis or ART (after 03 months of breastfeeding) and 18.1\% (19/105) mothers defaulted treatment at some time during pregnancy or breastfeeding.

\section{Prevalence of Mother to Child Transmission of HIV}

This study has found the prevalence of vertical transmission of HIV-1 is $0.0 \%(0 / 64)$ among mothers that received prophylaxis then started ART during pregnancy and breastfeeding, 7.1\% $(2 / 28)$ among mother that received only prophylaxis during pregnancy and breastfeeding and $38.4 \%(5 / 13)$ among mothers that never receive prophylaxis or ARVs during pregnancy and first 03 months of breastfeeding (Table 1).

\section{Risk factors of vertical Transmission of HIV-1 in the Gambia}

It was also found out that $15.8 \%(3 / 19)$ were positive among women that defaulted treatment at some time during pregnancy or breastfeeding while $31.2 \%$ (5/16) were positive among women who late to start prophylaxis/ART (started after 03 months of breastfeeding). These were found to be significantly associated with vertical transmission with $\mathrm{p}=0.022$ and $\mathrm{p}=0.001$ respectively.

The study has also found that $40 \%(2 / 5)$ were positive among first born of twins with a $\mathrm{p}=0.000$ (very significant association). All HIV-exposed infants are put on ART from birth and during breastfeeding and no HIV-infant mortality was registered since the intervention of ARVs in both rural and urban settings (Table 2).

All the 109 infants (100\%) were on exclusive breastfeeding and no Mixed-feeding or Formula- feeding was found No risk association was done since all the 109 infants were on exclusive breastfeeding.

Vertical Transmission Among Health Facilities in The Gambia

Table 1. Rate of vertical Transmission of HIV.

\begin{tabular}{|c|c|c|c|c|}
\hline & Total & HIV + & HIV-- & Rate \% \\
\hline $\begin{array}{c}\text { Mother received HIV-prophyl axis then started ART } \\
\text { during pregnancy and breastfeeding }\end{array}$ & 64 & 0 & 64 & $0.00 \%$ \\
\hline $\begin{array}{c}\text { Mother received only HIVprophyl axis during preg- } \\
\text { nancy and breastfeeding }\end{array}$ & 28 & 2 & 26 & $7.1 \%$ \\
\hline $\begin{array}{c}\text { Mother never receive HIVprophyl axis or ART during } \\
\text { pregnancy or first 03 months of breastfeeding }\end{array}$ & 13 & 5 & 8 & $38.4 \%$ \\
\hline
\end{tabular}

Table 2. Risk Factors Associated with Vertical Transmission of HIV-1 in the Gambia.

\begin{tabular}{|c|c|c|c|c|c|}
\hline & Total & HIV + & HIV-- & Rate $\%$ & p-value \\
\hline $\begin{array}{c}\text { Mother late to start prophylaxis or ARV } \\
\text { (after 03 months of breastfeeding) }\end{array}$ & 16 & 5 & 11 & $31.20 \%$ & $\mathrm{p}=0.001$ \\
\hline $\begin{array}{c}\text { Mother defaulted treatment at some time } \\
\text { during pregnancy or breastfeeding }\end{array}$ & 19 & 3 & 16 & $15.80 \%$ & $\mathrm{p}=0.002$ \\
\hline First born of a twins & 5 & 2 & 3 & $40 \%$ & $\mathrm{p}=0.001$ \\
\hline Exclusive breastfeeding & 109 & 7 & 102 & - & Not Sig \\
\hline
\end{tabular}


The rate of vertical transmission of HIV is higher in Soma Health Center and Sibanor Health Center where each facility representing $28.6 \%$ of the total number of positive infants. Brikama Health Center (Hands On Care), Serrekunda General Hospital and Basse Major Health Center represent $14.3 \%$ each while no vertical transmission was registered from other health facilities (Figure 1).

\section{Discussion}

This study has found the prevalence of vertical transmission of
HIV among women that received the HIV prophylaxis then start ART (lifelong therapy) during pregnancy and breastfeeding is at $0.0 \%$, while $7.1 \%$, among those that received HIV prophylaxis only, and unlike HIV infected women who never receive HIVprophylaxis or ART during pregnancy or breastfeeding, the rate of vertical transmission is at $38.4 \%$. A similar study done in Nigeria [1] and Burkina Faso [22], both revealed a vertical transmission rate of $0.0 \%$ among women receiving ART while $4.8 \%$ and $1.75 \%$ among women who received only prophylaxis respectively. Risk factors of vertical transmission such as late

Figure 1. Vertical Transmission of HIV Among Health Facilities.

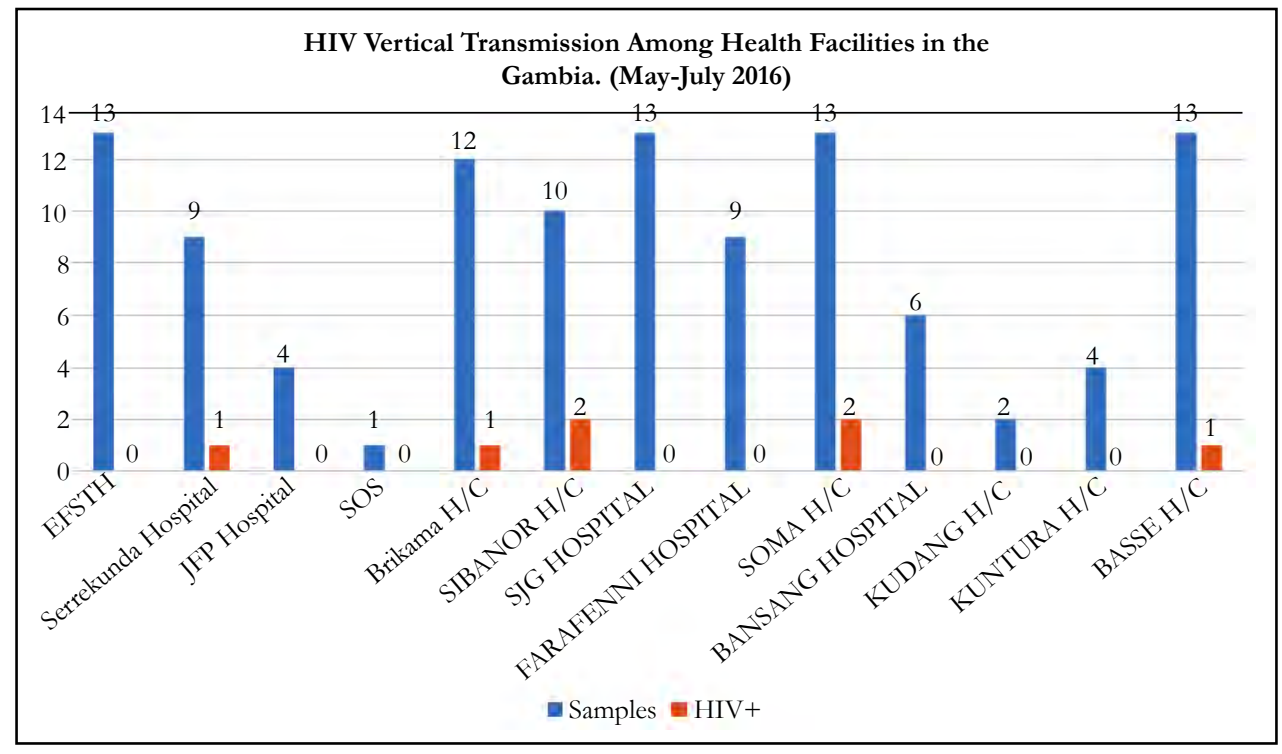

initiation of treatment, default during treatment and first born of twin were found to be significantly associated with vertical transmission, $\mathrm{p}=0.001, \mathrm{p}=0.022$ and $\mathrm{p}=0.000$ respectively.

Late initiation of treatment and default during treatment are considered as the highest risk factors, $71 \%$ mothers of the infected infants started the therapy after three months of breastfeeding while 39\% mothers of infected infants have defaulted treatment at certain point during treatment. This has also conceded with a similar observation made in Thailand, approximately $83 \%$ of HIV infected infants were born to mothers that lately initiate the ART and 59\% among these women are living in rural setting. This was related to limited PMTCT/ART sites in the rural settings in Thailand [16]. Thus establishment of more PMTCT/ART sites and decentralization of these sites would reduce the default of treatment among these women.

This research has also revealed out a very significant association $(p=0.000)$ between first born of twins and vertical transmission of HIV. Approximately 29\% (2/7) positive infants are first born twin, though only one of the mothers received HIV prophylaxis and the other never received prophylaxis or ARVs. According to (Caplan, A. et al., 2013) [3], this could be associated with complications and higher risk of contracting maternal blood during delivery of the first born. The probability that breastfeeding is related to the increase in risk of transmission could not be establish, because all the 109 infants are/were on exclusive breastfeeding.

In addition, all the 105 mothers (100\%) are given Cotrimazole (amoxicillin as alternative) as prophylaxis for opportunistic infections, this study has found out that defaulting during treatment is also related to the occurrence of opportunistic infection as $77.5 \%$ of patients that defaulted treatment at a point during treatment experience an opportunistic infections. Approximately $34 \%$ of mothers with positive infants were found to lost to follow up, with this regards, a proper uptake of HIV drugs should be ensure and a strengthening of follow-up of HIV pregnant women should be enhance.

Several similar studies done in Africa such as in Burkinafaso, Kenya, Nigeria, Tanzania and in Thailand [1, 5, 16, 18, 22], have all reported a low prevalence (less than $4 \%$ ) of vertical transmission among women on ART and in addition, they have revealed that the intervention of ARVs will not only reduce vertical transmission but it can reduce the risk of heterosexual transmission of HIV.

\section{Conclusion}

This study has found that the early intervention of ART at the onset of pregnancy through breastfeeding can eliminates Maternal to Child transmission of HIV and a high risk of vertical transmission was found among women who neither receive prophylaxis nor ART. This provides evidence of the effectiveness of the ART program, however, If the effectiveness of the antiretroviral therapy is maintain, the Gambia, in the near future will attain the WHO's goal to eliminate Maternal to Child transmission of HIV. 


\section{Limitations of This Study}

The RealTime Abbott PCR use in the Gambia can only detect proviral-DNA of HIV-1 thus only HIV-1 patients were included in this study. Lack of enough information on mother's CD4/CD8 cell count and viral load, however, the analysis would have been strengthened by including these variables.

\section{Recommendations}

Though the intervention of ARVs drastically reduce vertical transmission of HIV, however, the HIV virus has a high resistance rate capacity and can develop resistance to most of these ARV drugs, which could limit future treatment. Thus a constant monitoring and surveillance of HIV drug resistance is required.

\section{Acknowledgements}

The authors wish to acknowledge the study team at the National Public Health Laboratory for all the laboratory work and Université Cheikh Anta Diop for the supervision. We wish to acknowledge the study participants for their willingness to participate.

The National AIDS Secretariat, National AIDS Control Program $\&$ MOHERST funded and supported this study

\section{References}

[1]. Anoje C, Aiyenigba B, Suzuki C, Badru T, Akpoigbe K, et al., (2012) Reducing mother to-child transmission of HIV : findings from an early infant diagnosis program in south-south region of Nigeria. BMC Public Health. 12(1): 184.

[2]. Arachchilage MH, Piontkivska H (2016) Coevolutionary Analysis Identifies Protein-Protein Interaction Sites between HIV-1 Reverse Transcriptase and Integrase. Virus Evol. 2(1).

[3]. Caplan A, Prazuck T, Chaillon A, Niang M, Barin F, et al., (2013) HIVDNA in the Genital Tract of Women on Long-Term Effective Therapy Is Associated to Residual Viremia and Previous AIDS-Defining Illnesses. Plos One. 8(8): e69686

[4]. Engelman A, Cherepanov P (2012) The structural biology of HIV - 1: mechanistic and therapeutic insights. Nat Rev Microbiol. 10(4): 279-290.

[5]. Goggin K, Wexler C, Nazir N, Staggs VS, Gautney B, et al., (2016) Predictors of Infant Age at Enrollment in Early Infant Diagnosis Services in Kenya. AIDS Behav. 20(9): 2141-2150.

[6]. Guadalupe M, Schacker TW, Reay E, Flamm J, McNeil A, et al., (2003) Severe CD4+ T-cell depletion in gut lymphoid tissue during primary human immunodeficiency virus type 1 infection and substantial delay in restoration following highly active antiretroviral therapy. J Virol. 77(21): 11708-11717.

[7]. Idele P, Gillespie A, Porth T, Suzuki C, Mahy M, et al., (2014) Epidemiology of HIV and AIDS Among Adolescents : Current Status , Inequities, and Data Gaps. J Acquir Immune Defic Syndr. 66(2): 144-153.

[8]. Jamieson DJ, Chasela CS, Hudgens MG, King CC, Athena P, et al., (2013) Maternal and infant antiretroviral regimens to prevent postnatal HIV-1 transmission: 48-week follow-up of the BAN randomised controlled trial. 379(9835): 2449-2458.
[9]. Kerr RJS, Player G, Fiscus SA, Nelson JAE, Hill C, et al., (2009) Qualitative Human Immunodeficiency Virus RNA Analysis of Dried Blood Spots for Diagnosis of Infections in Infants. J Clin Microbiol. 47(1): 220-222.

[10]. A. Kumar, DD Jones, MA Hanna, B Soediono, AC Bartocci (2009) "Effect of a Monoclonal Antibody to PCSK9 on LDL Cholesterol". J. Chem. Inf. Model., 53(3): 556-581.

[11]. Lemey P, Pybus OG, Rambaut A, Drummond AJ, Robertson DL, et al., (2004) The Molecular Population Genetics of HIV-1 Group O. Genetics. 167(3): 1059-1068.

[12]. Mercier-delarue S, Vray M, Plantier C, Maillard T, Adjout Z, et al., (2014) Higher Specificity of Nucleic Acid Sequence-Based Amplification Isothermal Technology than of Real-Time PCR for Quantification of HIV-1 RNA on Dried Blood Spots. J Clin Microbiol. 52(1): 52-56.

[13]. MoHSW \& WHO (2015) Guidelines for Antiretroviral Therapy for the Prevention and Treatment of HIV in Gambia. October 2015.

[14]. National AIDS Secretariat (NAS) report on National Strategic Plan for HIV and AIDS 2015/2016 to 2019/2020.

[15]. Naidoo Sarita, Handan Wand, Nathlee Samantha Abbai, Gita Ramjee (2014) "High prevalence and incidence of sexually transmitted infections among women living in Kwazulu-Natal, South Africa”. AIDS res ther. 11(1): 31.

[16]. Naiwatanakul T, Voramongkol N, Punsuwan N, Lolekha R, Gass R, et al., (2016) Uptake of early infant diagnosis in Thailand 's national program for preventing mother-to-child HIV transmission and linkage to care, 20082011. J Int Aids Soc. 19(1): 20511

[17]. Negedu-momoh OR, Olonitola OS, Odama LE, Inabo HI, Mbah HA, et al., (2014) Antiretroviral-Drug Resistant Mutations and Genetic Diversity in HIV-1 Infected Individuals in Nigeria. Sci Res. 4(2): 187-197.

[18]. Nuwagaba-biribonwoha H, Werq-semo B, Abdallah A, Cunningham A, Gamaliel JG, et al., (2010) Introducing a multi-site program for early diagnosis of HIV infection among HIV-exposed infants in Tanzania. BMC Pediatr. 10: 44 .

[19]. Rambaut A, Posada D, Crandall KA, Holmes EC (2004) The causes of HIV Evolution. Nat Rev Gentics. 5: 52-61.

[20]. Read JS (2007) Diagnosis of HIV-1 Infection in Children Younger Than 18 Months in the United States. Pediatrics. 120(6): 1547-1562.

[21]. Rossi Ade, Zanchetta M, Vitone F, Antonelli G, Bagnarelli P, et al., (2010) Quantitative HIV-1 proviral DNA detection : a multicentre analysis. New Microbiol. 33(4): 293-302.

[22]. Sagna T, Bisseye C, Compaore TR, Therese S, Djigma FW, et al., (2015) Prevention of mother-to-child HIV-1 transmission in Burkina Faso: evaluation of vertical transmission by PCR, molecular characterization of subtypes and determination of antiretroviral drugs resistance. Glob Health Action. 8: 10.

[23]. Shafer RW, Dupnik K, Winters MA, Eshleman SH (2001) A Guide to HIV1 Reverse Transcriptase and Protease Sequencing for Drug Resistance Studies. HIV Seq Compend. 2001: 1-51.

[24]. Sharma G, Kaur G, Mehra N (2011) Genetic correlates influencing immunopathogenesis of HIV infection. Indian J Med Res. 134(6): 749-768.

[25]. Shi SP (2011) Investigating the Anti-Viral Property of Verotoxin and its Receptor Gb 3 in Preventing Primary HIV-1 Infection. Doctoral dissertation, University of Toronto).

[26]. Smith J (1995) Detection of Human Immunodeficiency Virus Type 1 Proviral DNA by PCR Using an Electrochemiluminescence-Tagged Probe. J Clin Microbiol. 33(8): 2036-2041.

[27]. Smit PW, Sollis KA, Fiscus S, Ford N, Vitoria M, et al., (2014) Systematic Review of the Use of Dried Blood Spots for Monitoring HIV Viral Load and for Early Infant Diagnosis. 9(3): 1-8.

[28]. American Academy of Pediatrics Committee on Pediatric AIDS (2008) HIV Testing and Prophylaxis to Prevent Mother-to-Child Transmission in the United States. Pediatrics. 122(5): 1127-34.

[29]. Wittek M, Stürmer M, Doerr HW, Berger A (2007) Molecular assays for monitoring HIV infection and antiretroviral therapy. Expert Rev Mol Diagn. $7(3): 237-246$. 